\title{
FLEXIBLE CELLS AND MODULES PRODUCED USING ROLL-TO-ROLL ELECTROPLATING APPROACH
}

\author{
Mustafa Pinarbasi, Serdar Aksu, James Freitag, Thomas Boone, Howard Zolla, Jorge Vasquez, \\ Deepak Nayak, Eric Lee, Tony Wang, Jehad Abushama, Burak Metin \\ SoloPower Inc., San Jose, CA, USA
}

\begin{abstract}
Thin film $\mathrm{Cu}(\mathrm{In}, \mathrm{Ga}) \mathrm{Se}_{2}$ (CIGS) photovoltaic cells are considered to have a high potential for low cost electricity production due to their demonstrated high conversion efficiencies. Various methods have been used to make thin film CIGS solar cells. In the present approach, a low cost roll-to-roll electroplating process is utilized to deposit the CIGS precursor layers. The electroplating technology provides well controlled composition along the length and width of the flexible substrates demonstrating its suitability as a low cost CIGS precursor deposition method. Precursor layers are then subjected to rapid thermal processing to form a photovoltaic-grade CIGS absorber. The processing is done using roll-to-roll production equipment on a flexible metallic substrate. The CIGS based solar cells are fully finished in roll form and then cut into large area cells. The cells are then interconnected to fabricate panels with about $1.1 \mathrm{~m}^{2}$ aperture area and about $115 \mathrm{~W}$ power output. These rigid panels show excellent stability under damp heat test conditions and are certified against both UL and IEC standards. More recent work has focused on lightweight flexible solar modules. These modules open new application areas and can further lower the cost of systems by lowering the installation costs. Flexible modules with aperture area efficiency as high as $11.2 \%$ have been demonstrated. Standard module certification tests, including 1000 hour damp heat test, show very small changes of Pmax.
\end{abstract}

\section{INTRODUCTION}

$\mathrm{Cu}(\mathrm{In}, \mathrm{Ga}) \mathrm{Se}_{2}$ (CIGS) is an excellent absorber material for thin film solar cells due to its direct bandgap, high absorption coefficient, and ability to yield good quality devices. CIGS-based solar cells have yielded the highest conversion efficiencies of all thin film solar cells, reaching up to about $20 \%$ [1]. Although successful in yielding small area, high efficiency laboratory cells, co-evaporation techniques are costly and difficult to scale up. The material utilization rates of such processes are also low. Two-stage processing for CIGS synthesis, in which the CIGS layer is formed through two process steps, offers a lower cost structure and easier manufacturability. In the first step of this technique, a precursor layer comprising $\mathrm{Cu}, \mathrm{In}, \mathrm{Ga}$ and possibly $\mathrm{Se}$ is deposited on a substrate at room temperature. In the second step, the precursor layer is treated in a high temperature process environment, typically at atmospheric pressure, to convert the precursor into device quality CIGS film. Although various techniques such as evaporation and sputtering have been employed to prepare precursor layers, electrodeposition offers several advantages. Electrodeposition is a versatile deposition method with ability to yield thin films of metals, metal alloys and compounds which may be used in a wide variety of precursor layer structures. In addition, electrodeposition equipment is low cost and energy efficient since it is typically carried out at low temperatures. Moreover, materials utilization in electrodeposition processes can be close to $100 \%$ if stable electrolytes with long lifetime are employed. Electrodeposition is also suitable for high throughput roll to roll manufacturing.

A wide range of processing approaches employing electrodeposition has been explored for CIGS film formation during the last two decades. These approaches include; i) electrodeposition of thin $\mathrm{Cu}$ and In layers forming a Cu/ln precursor stack and reacting this metallic stack with gaseous Se species to form the compound [2], ii) electrodeposition of a Cu/In/Se stack on a substrate and rapid thermal annealing of the stack to form CIS [3], iii) electrodeposition of In-Ga [4], Cu-Ga [5] or Cu-In-Ga [6] metal alloys to form precursor layers and reacting these precursor layers to form the compound, iv) electrodeposition of $\mathrm{In}-\mathrm{Se}$ and $\mathrm{Cu}-\mathrm{Se}$ on a substrate forming a stacked precursor such as a Cu/ln-Se/Cu-Se structure and annealing the structure in inert atmosphere to form CIS [7], and v) one step electrodeposition of CIS or CIGS compound films and subjecting them to high temperature crystallization step to improve their photovoltaic properties [8]. Reader is referred to Lincot et al. [9] for a more detailed review of these various electrodeposition approaches.

In one of the previous publications, we described the electrolytes and methods for the electrodeposition of In-Se and Ga-Se films [10], which can be used for the preparation of $\mathrm{Ga}$ containing precursors and CIGS layers. Using SoloPower's patented electroplating process, cell efficiencies close to $13.8 \%$ on $0.5 \mathrm{~cm}^{2}$ and over $12.2 \%$ on $100 \mathrm{~cm}^{2}$ were previously demonstrated on flexible stainless steel substrates $[11,12]$. In this paper summary of the recent results for roll to roll processing of CIGS absorber will be given and performance of the flexible modules will be presented. 


\section{EXPERIMENTAL}

\section{Roll to roll Processing}

CIGS layers are formed on $50 \mu \mathrm{m}$ thick flexible stainless steel foil. . The width of the foil substrates is 0.34 meters and can be up to 500 meter long. After cleaning, rolls are coated with a Mo-based contact layer using a roll-to-roll sputtering tool. The rolls are then transferred to the electrodeposition station where a Cu-In-Ga-Se precursor film containing the preselected composition is electrodeposited on the contact layer in a roll-to-roll electroplating machine. The precursor layers are then subjected to an RTP-type annealing/crystallization process step which converts them into device-quality CIGS layers. The typical temperature range employed in this process step is $500-550{ }^{\circ} \mathrm{C}$, although CIGS film formation could be achieved in a wider temperature range of $450-600^{\circ} \mathrm{C}$. The thickness of the CIGS layers is in the range of $1-2 \mu \mathrm{m}$. Continuous compositional analysis of the precursor layers is carried out by XRF measurements on the electroplating tool as the deposition takes place. Results are also confirmed by inductively coupled plasma (ICP) analysis after cutting coupons from various regions of the processed rolls and then chemically dissolving these coupons to prepare ICP samples.

Typically, a $100 \mathrm{~nm}$ thick CdS buffer layer is deposited on the CIGS absorber by the chemical bath deposition (CBD) approach using a roll-to-roll deposition system. An intrinsic- $\mathrm{ZnO} /$ conductive-TCO stack is then deposited over the buffer layer using a roll-to-roll sputtering tool. The sheet resistance value of the TCO layer is in the range of 40-60 $\Omega / \square$ and the transmission within the visible range of the spectrum is over $90 \%$.

The roll of the solar cell stack obtained after the TCO sputtering step is coated with a large number of silverbased finger patterns using a roll-to-roll screen printing tool, which employs a low temperature ink that can be cured at below $250^{\circ} \mathrm{C}$. At the completion of this process step, a roll containing thousands of solar cells is obtained.

In our research laboratory, CIGS solar cells are also fabricated in a similar sequence using batch processing tools. The cell area for the research studies is about 12 $\mathrm{cm}^{2}$ to ensure that processes developed in the lab can easily be transferred to roll to roll production tooling.

\section{Cell and module fabrication and testing}

Grid patterns deposited on the roll of solar cell structure define the shape and the size of the devices that are later cut from the roll. An automated roll-to-roll cutter cuts the cells from the rolls based on the pre-selected size of the devices. Cut cells are sorted and binned according to their current and efficiency values using an automated testing/sorting tool (Figure 1). Sorted and binned flexible cells are then interconnected using standard copper ribbons to form cell strings. The stringing method uses conductive adhesives which are cured at temperatures below $250 \stackrel{\circ}{\circ} \mathrm{C}$. Modules with glass front-sheets and flexible front-sheets are fabricated in a standard vacuum lamination machine. The back sheet is a flexible polymeric foil. I-V characteristics of the cells and modules were measured at SoloPower and selected ones were verified at NREL under standard test conditions $\left(25^{\circ} \mathrm{C}, \mathrm{AM} 1.5\right.$, and $1000 \mathrm{~W} / \mathrm{m}^{2}$ irradiance).

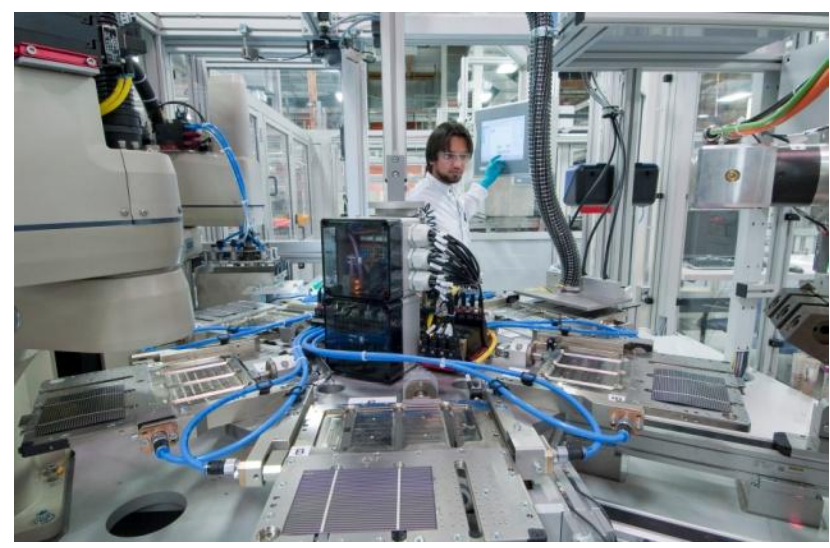

Figure 1: An automated testing/sorting tool is used for measuring the I-V cell parameters of cells cut from the finished rolls and binning the measured cells according to the their currents and efficiencies.

\section{RESULTS AND DISCUSSIONS}

\section{CIGS processing}

One of the most critical aspects of the CIGS formation is composition control. Detailed results on the electroplated CIGS composition control and its impact on the cell efficiencies were discussed previously (12). The robustness of the cell properties against small composition variations enhances the manufacturability of the deposition technique. As an example of this flexibility, the electrical performance of cells produced from three different precursor electro-plating recipes is presented in Figure 2. Here the roll-to-roll plating current vs. distance for the Copper, Indium and Gallium is compared against efficiency, Voc and Jsc over a 110 meter section of a roll. Note that the three distinct plating conditions resulted in significantly different precursor $\mathrm{Cu} /(\mathrm{In}+\mathrm{Ga})$ and $\mathrm{Ga} /(\mathrm{In}+\mathrm{Ga})$ ratios. Despite the abrupt changes in composition, the efficiency for conditions I and II are nearly indistinguishable. However, a closer examination of the Voc and Jsc characteristics show that the larger $\mathrm{Ga} /(\mathrm{In}+\mathrm{Ga})$ increased the bandgap as expected resulting in a shift to higher Voc and lower Jsc. The efficiency did begin to degrade in the lowest $\mathrm{Ga} /(\mathrm{In}+\mathrm{Ga})$ ratio. However, this is a far larger shift than would ever be encountered from typical process drift. Therefore, subtle shifts in composition due to processing variations will not degrade the performance for electroplated CIGS with two stage process. Another observation is that the Voc or Jsc of the 
CIGS material can be controlled by changing the conditions of the electroplating process while efficiency remains constant.

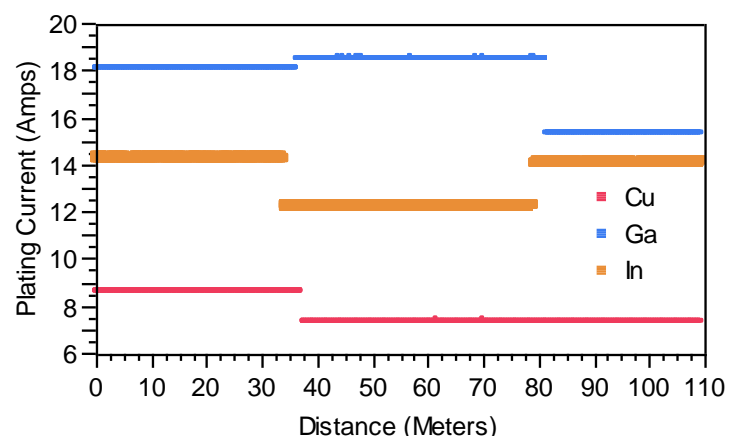

(a)

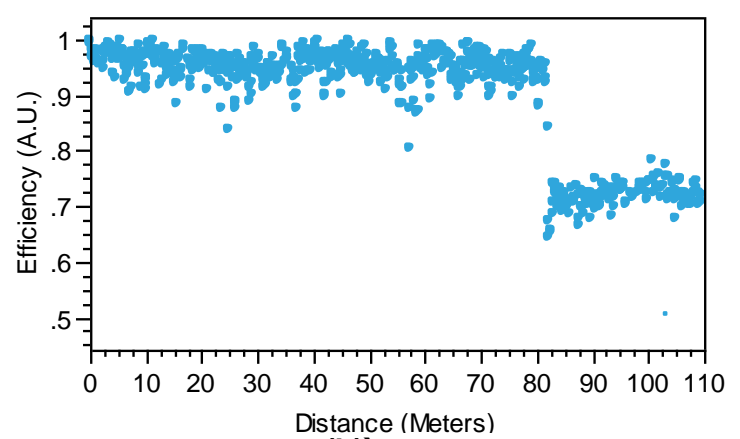

(b)

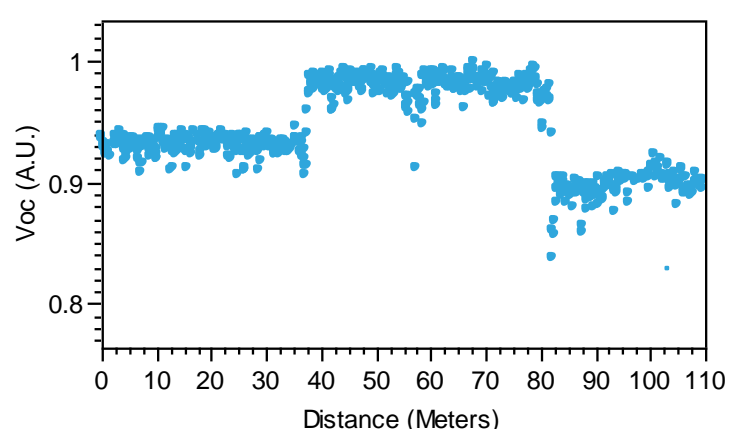

(c)

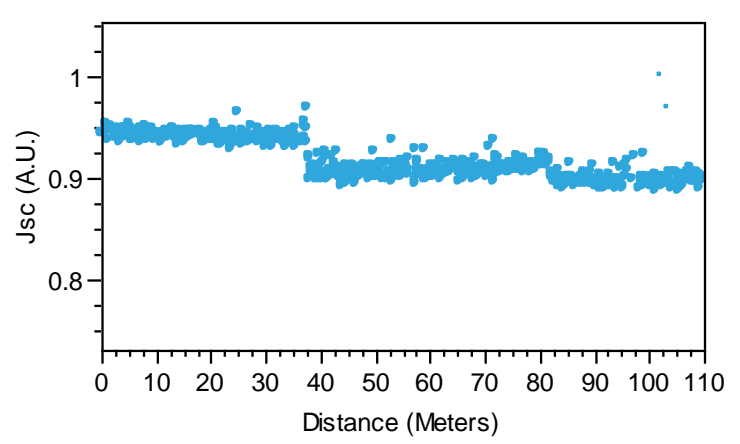

(d)
Figure 2 (left) : a) Plating current versus distance from an 110 meter section of a roll for the $\mathrm{Cu}, \mathrm{Ga}$ and In precursor plating cells for a CIGS process. b) Efficiency, c) Voc and d) Jsc for the same sections illustrating the robustness of CIGS efficiency to slight compositional changes. Note that Voc and Jsc do change according to bandgap shifts associated with $\mathrm{Ga} /(\mathrm{In}+\mathrm{Ga})$ ratio. Performance degradation is observed for compositional swings larger than a typical process drift due to time or non-uniformity.

Another critical challenge for CIGS manufacturability is the lateral uniformity requirement for high performance cells. This is illustrated in Figure 3 where a lane of $120 \mathrm{~cm}^{2}$ cells in a roll suffered from a particularly low efficiency and Voc. When smaller $12 \mathrm{~cm}^{2}$ cells were fabricated from the same section of material it was discovered that only a small sublane of the material was actually limiting the cumulative cell performance. This is further illustrated by electroluminescent (EL) imaging and laser beam induced current (LBIC) mapping measurement performed on the same cell. Here the dark band observed in both techniques suggests a low $\mathrm{Voc}$ and Jsc in the A1 region of the cell caused by poor material quality. It was later determined that a band of low-Indium composition was present in this region. Physically, this composition reduced the minority carrier lifetime in this region, reducing the overall performance by $30 \%$. This situation therefore underscores the importance of in-line monitoring of the lateral uniformity during CIGS process to maintain the highest total cell performance.
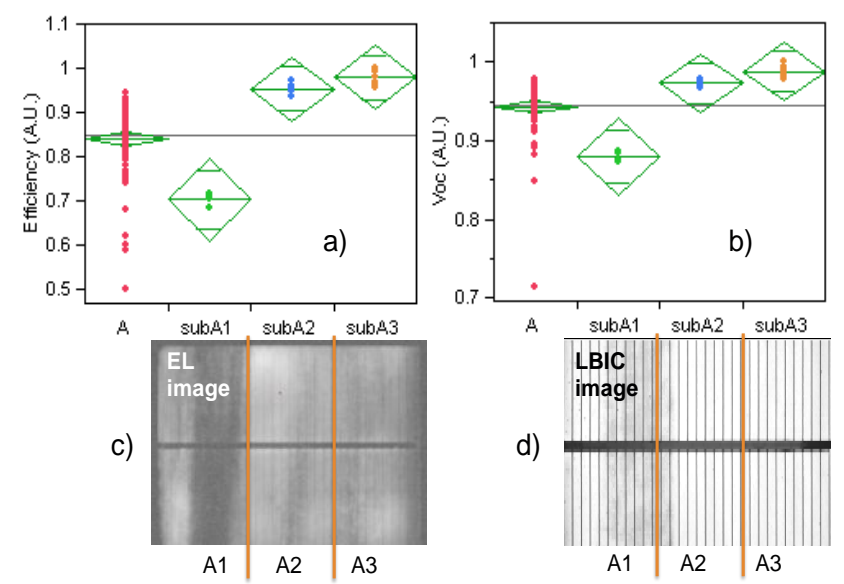

Figure 3: a) Efficiency and b) Voc for the A lane of a 120 $\mathrm{cm}^{2}$ cells from a CIGS roll to roll process compared with three lanes of $12 \mathrm{~cm} 2$ cells covering the same section of material. Here we see that a small sub-lane is ultimately limiting the total performance of the cell. The cause of this reduced performance was determined to be due to a compositional shift which resulted in a lower minority carrier lifetime semiconductor. This is further demonstrated by the dark section of an C) EL image and an d) LBIC image taken from the same cell. 


\section{Cell and module measurements}

Figure 4 shows the illuminated I-V characteristics of a 11.8 $\mathrm{cm}^{2}$ area solar cell fabricated in our research laboratory.

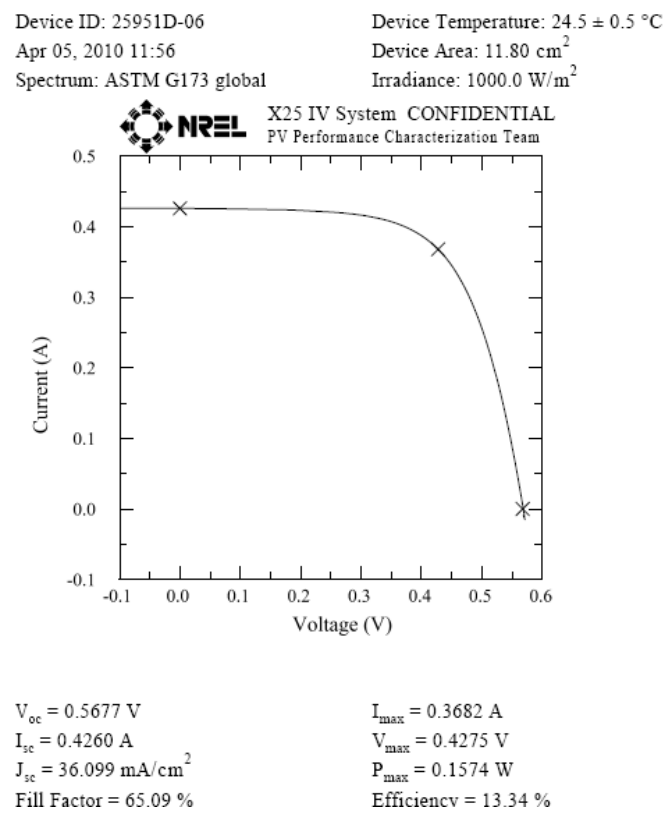

Figure 4: Shows the illuminated I-V characteristics of an $11.8 \mathrm{~cm}^{2}$ area device.

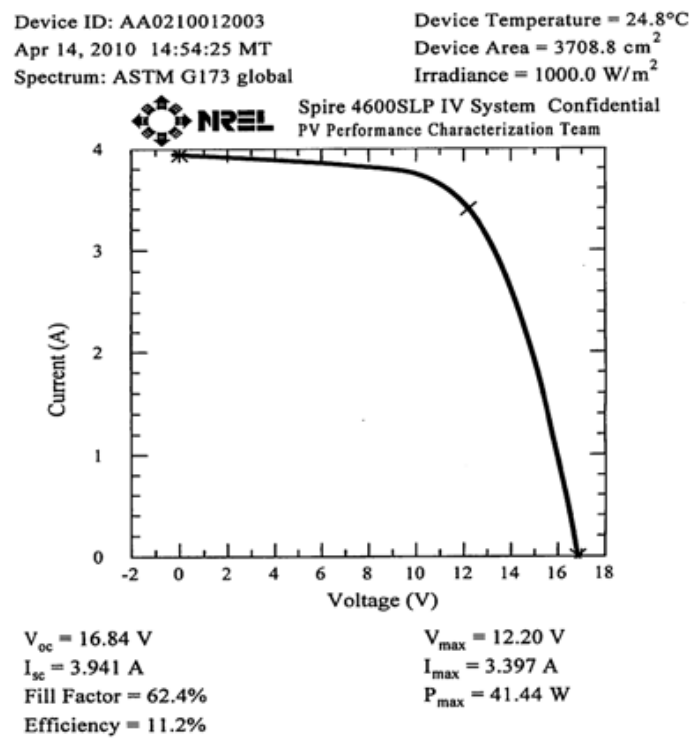

Figure 5: The illuminated I-V characteristics of a 1.5 meter long flexible solar panel with $11.2 \%$ efficiency.
The total area efficiency of the device shown in Figure 4 is $13.43 \%$. The $\mathrm{V}_{\mathrm{oc}}, \mathrm{J}_{\mathrm{sc}}$, and FF values are $0.568 \mathrm{~V}, 36.19$ $\mathrm{mA} / \mathrm{cm}^{2}$, and $65.36 \%$, respectively. This efficiency value corresponds to an active area efficiency of about $14.67 \%$. Improved electroplated precursor preparation and RTP processes are responsible for the improved cell efficiencies. These novel processes are currently being transferred to roll-to-roll production line.

The illuminated I-V characteristics of a SoloPower flexible panel is shown in Figure 5. This panel was 1.5 meters long and produced in the SoloPower manufacturing line. Outdoor performance tests showed similar efficiencies for modules that are 3 meters long. Using low weight front sheet material brings the total weight of the flexible modules to $\sim 2.6 \mathrm{~kg} / \mathrm{m}^{2}$. In an earlier publication, we demonstrated rigid modules fabricated in our roll-to-roll line achieved $10 \%$ efficiency level [12]. Improvement of efficiencies from $10 \%$ (rigid) to $11.2 \%$ (flexible) shows the improvements in our cell processing in less than a year. The material set used to produce the flexible panels were similar to the material set used for rigid panel with the key difference being the replacement of the front glass with a flexible front sheet.

\section{Rigid panels}

SoloPower's rigid modules have been certified against UL1703, IEC61646, and IEC61730 industry specifications for photovoltaic products. UL and IEC certification for rigid panels were completed in June and August of 2009 respectively. Rigid product (Figure 6) arrays tested in an outdoor test facility since 2009 show robust reliability, with no power loss over a year of operation.

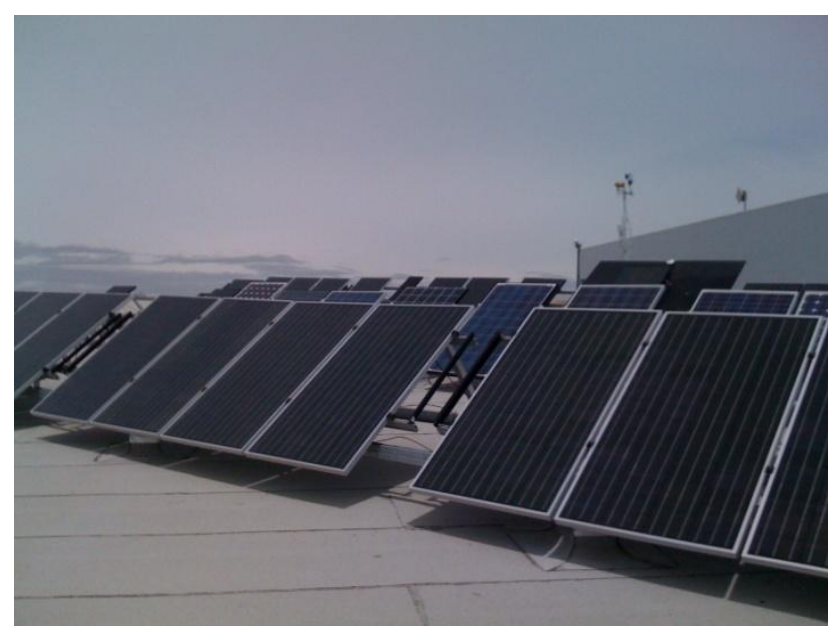

Figure 6: Glass module array in Solopower's outdoor test facility, San Jose, CA.

Solopower's rigid "SP-1" panels have been tested for an extended period of time, up to 2800 hours under damp heat conditions. Figure 7 shows the power loss to be 
around $10 \%$ after nearly 2800 hours of damp heat exposure. These data show that components used in SoloPower products are robust in adverse conditions. Temperature Cycle testing, done at $-40^{\circ} \mathrm{C} / 90^{\circ} \mathrm{C}$ for 200 cycles, is required for $\mathrm{UL}$ and IEC certification. Our rigid panels (SP-1) have been tested for an extended period of time, up to 500 cycles. Power loss in these panels is again around $10 \%$ after about 500 cycles of testing, confirming the high quality of components used (Figure 8).

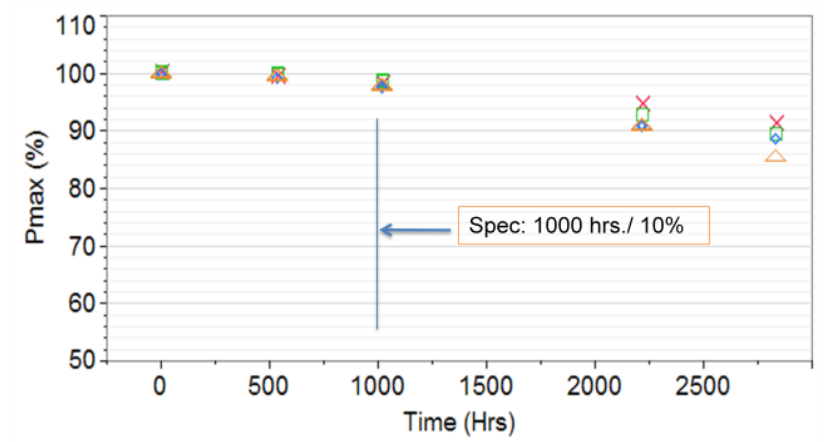

Figure 7: Damp heat test of glass panels at $85^{\circ} \mathrm{C} /$ $85 \% \mathrm{RH}$.

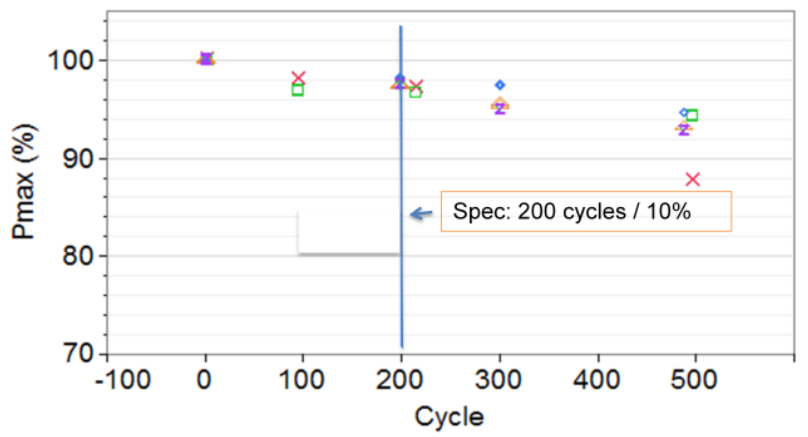

Figure 8: Temperature cycle test of rigid panels at $-40^{\circ} \mathrm{C} / 90^{\circ} \mathrm{C}$.

\section{Flexible and low weight panels}

Solopower's flexible panels share most of the components used for the rigid modules such as cells, back sheet, encapsulation, ribbon, interconnect, adhesives, edge seals, and lamination process. The key difference is that the flexible front sheet with moisture barrier replaces the glass front sheet.

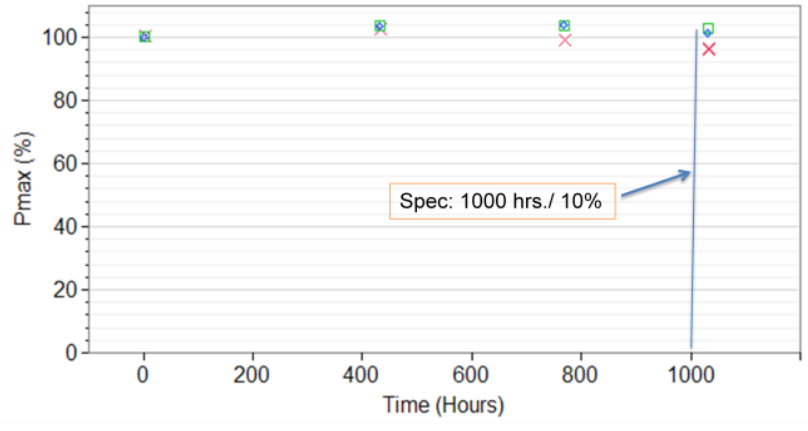

Figure 9: Damp heat test of flexible modules at $85^{\circ} \mathrm{C} / 85 \%$ relative humidity.

Damp heat is one of the most critical test for any flexible module as the flexible front sheet barrier must provide protection against moisture over the life of the product. We have tested several modules from the manufacturing line. Damp heat tests conducted on these flexible panels (SFX1-i) showed no power loss after 1000 hours as shown in Figure 9. This is similar to the data that we have observed for rigid modules after 1000 hours of damp heat exposure.

Flexible panels were also subjected to temperature cycle testing $\left(-40^{\circ} \mathrm{C} / 90^{\circ} \mathrm{C}\right)$. Results shown in Figure 10 demonstrate that very small or no power degradation is observed after 350 cycles.

Another critical UL test is the Humidity Freeze Test, where modules are subjected to $85 \%$ relative humidity and temperature cycle of $-40^{\circ} \mathrm{C}$ to $85^{\circ} \mathrm{C}$ alternately. As shown in Figure 11, SoloPower flexible modules show no power degradation after 10 humidity freeze cycles.

Although these tests may not directly correlate to outdoor performance they nonetheless reveal critical information about the robustness of the components and production processes used.

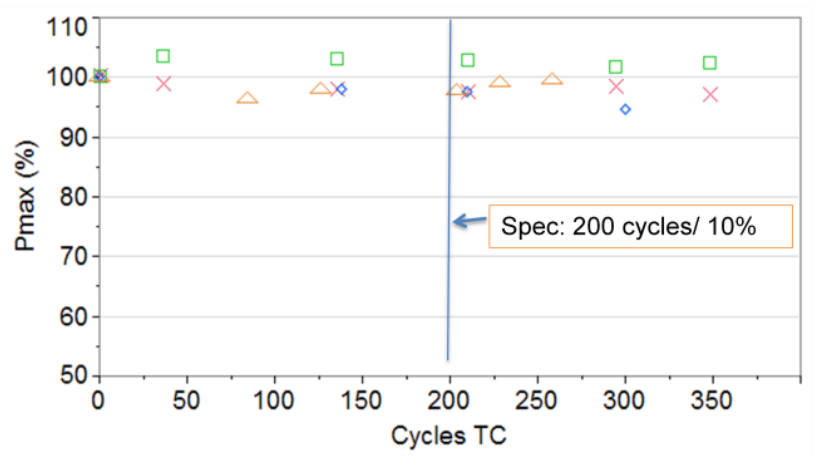

Figure 10: Temperature cycle test of rigid panels at $-40^{\circ} \mathrm{C}$ / $90^{\circ} \mathrm{C}$. 


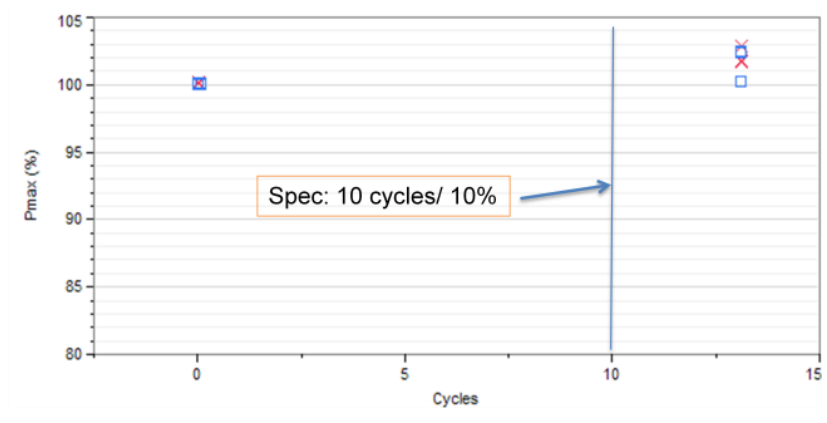

Figure 11: Humidity Freeze test of flexible modules.

\section{CONCLUSIONS}

A summary of the results for the electrodeposited CIGS on flexible metal foils at SoloPower was given and performance aspects of the rigid and flexible modules were presented. The electrodeposition process has the capability to control the $\mathrm{Cu} /(\mathrm{In}+\mathrm{Ga})$ and $\mathrm{Ga} /(\mathrm{In}+\mathrm{Ga})$ metal ratios reliably. CIGS layers are formed through RTP of the electrodeposited precursors. Solar cells are fabricated in a roll and then cut and sorted for module manufacturing. Both glass and flexible panels were made from interconnection of the cut cells. Flexible panels with aperture efficiency of $11.2 \%$ have been demonstrated. Detailed studies show that these panels perform well and retain their Pmax after every standard UL or IEC certification tests including the 1000 hour damp heat test.

\section{REFERENCES}

[1] I. Repins, M. A. Contreras, B. Egaas, C. DeHart, J. Scharf, C. L. Perkins, B. To and R. Noufi "19.9\% efficient $\mathrm{ZnO} / \mathrm{CdS} / \mathrm{CIGS}$ solar cell with $81.2 \%$ fill factor", Prog. Photovolt: Res. Appl. 16, 2008, pp. 235-239.

[2] V.K. Kapur, B.M. Basol and E.S. Tseng, "Low cost methods for the production of semiconductor films for CIS/CdS solar cells", Sol.Cells 21,1987, pp. 65-72.

[3] H.P. Fritz and P. Chatziagorastou, "A new electrochemical method for selenization of stacked Culn layers and preparation of CIS by thermal annealing", Thin Solid Films 247, 1994, pp. 129-133.

[4] J. Zank, M. Mehilin and H.P. Fritz, "Electrochemical codeposition of indium and gallium for chalcopyrite solar cells", Thin Solid Films 286, 1996, pp. 259-263.

[5 ] R. Friedfeld, R.P. Raffaelle and J.G. Mantovani, "Electrodeposition of CIGS thin films", Sol. Energ. Mat. Sol. C. 31, 1999, pp. 163-167.

[6] M. Ganchev, J. Kois, M. Kaelin, S. Bereznev, E. Tzvetkova, O. Volobujeva, N. Stratieva and A. Tiwari, "Preparation of CIGS layers by selenization of electrodeposited Cu-In-Ga precursors", Thin Solid Films 511-512, 2006, pp. 325-327.

[7] A. Fernandez, M. Calixto, P. Sebastian, S. Gamboa, A. Hermann and R. Noufi, "Electrodeposited and selenized CIS thin films for photovoltaic applications", Sol. Energ. Mat. Sol. C., 52, 1998, pp. 423-427.

[8] R. N. Bhattacharya, W. Batchelor, J. E. Granata, F. Hasoon, H. Wiesner, K. Ramanathan, J.Keane, and R. N. Noufi, Sol. Energ. Mat. Sol. C., 55, 1998, pp. 83-87.

[9] D. Lincot, J.F. Guillemoles, S. Taunier, D. Guimard, J. Sicx-Kurdi, A. Chaumont, O. Roussel, O. Ramdani, C. Hubert, J.P. Fauvarque, N. Bodereau, L. Parissi, P. Panheleux, P. Fanouillere, N. Naghavi, P.P. Grand, M. Benfarah, P. Mogensen, O. Kerrec, Sol. Energy, 77, 2004, pp. 725-729.

[10] S. Aksu, J. Wang and B. Basol, "Electrodeposition of In-Se and Ga-Se thin films for preparation of CIGS solar cells", Electrochem. and Solid-State Lett. 12, 2009, pp. D33-D35.

[11] B. Basol, M. Pinarbasi, S. Aksu, J. Wang, Y. Matus, T. Johnson, Y. Han, M. Narasimhan, and B. Metin,

"Electroplating based CIGS technology for Roll-to-Roll Manufacturing", Twenty third European PVSEC, 2008, pp. 2137-2141.

[12] B. Basol, M. Pinarbasi, S. Aksu, J. Freitag, P. Gonzalez, T. Johnson, Y. Matus, B. Metin, M. Narasimhan, D. Nayak, G. Norsworthy, D. Soltz, J. Wang, T. Wang, H. Zolla, "Status of electroplating based CIGS technology development" Thirty fourth IEEE PVSC, 2009, pp. 2310-2315. 